\title{
Possible implication of bacterial infection in acute graft-versus-host disease after allogeneic hematopoietic stem cell transplantation
}

\author{
Shigeo Fuji ${ }^{1,2}{ }^{*}$, Markus Kapp $^{1}$ and Hermann Einsele ${ }^{1}$ \\ ${ }^{1}$ Division of Hematology, Department of Internal Medicine II, University Hospital of Würzburg, Würzburg, Germany \\ 2 Division of Hematopoietic Stem Cell Transplantation, National Cancer Center Hospital, Tokyo, Japan
}

\section{Edited by:}

Khalid Ahmed Al-Anazi, King Saud

University, Saudi Arabia

\section{Reviewed by:}

Yashwant Kumar, Post Graduate

Institute of Medical Education and

Research, India

Lawrence E. Goldfinger, Temple

University School of Medicine, USA

Raman Chandrasekar, Kansas State

University, USA

\section{*Correspondence:}

Shigeo Fuji, Division of Hematopoietic Stem Cell Transplantation, National Cancer Center Hospital, 5-1-1 Tsukiji,

Chuo-Ku, Tokyo 104-0045, Japan

e-mail: sfuji@ncc.go.jp
Graft-versus-host disease (GVHD) is still one of the major causes of morbidity and mortality in allogeneic hematopoietic stem cell transplantation (HSCT). In the pathogenesis of acute GVHD, it has been established that donor-derived T-cells activated in the recipient play a major role in GVHD in initiation and maintenance within an inflammatory cascade. To reduce the risk of GVHD, intensification of GVHD prophylaxis like T-cell depletion is effective, but it inevitably increases the risk of infectious diseases and abrogates beneficial graft-versusleukemia effects. Although various cytokines are considered to play an important role in the pathogenesis of GVHD, GVHD initiation is such a complex process that cannot be prevented by means of single inflammatory cytokine inhibition. Thus, efficient methods to control the whole inflammatory milieu both on cellular and humoral view are needed. In this context, infectious diseases can theoretically contribute to an elevation of inflammatory cytokines after allogeneic HSCT and activation of various subtypes of immune effector cells, which might in summary lead to an aggravation of acute GVHD. The appropriate treatments or prophylaxis of bacterial infection during the early phase after allogeneic HSCT might be beneficial to reduce not only infectious-related but also GVHD-related mortality. Here, we aim to review the literature addressing the interactions of bacterial infections and GVHD after allogeneic HSCT.

Keywords: bacterial infection, GVHD, allogeneic hematopoietic stem cell transplantation, pathogen-associated molecular patterns, LPS

\section{INTRODUCTION}

Graft-versus-host disease (GVHD) is still one of the major causes of morbidity and mortality responsible for $10-20 \%$ of all deaths in allogeneic hematopoietic stem cell transplantation (HSCT) $(1,2)$. In the pathogenesis of acute GVHD, it has been established that donor-derived T-cells activated in the recipient play a major role in GVHD initiation and maintenance within a complex inflammatory cascade (3). To reduce the risk of GVHD, intensification of GVHD prophylaxis such as profound T-cell depletion is effective, but it inevitably increases the risk of infectious diseases and abrogates beneficial graft-versus-leukemia (GVL) effects. Another potentially beneficial intervention to reduce the risk of GVHD could be the suppression of inflammatory cytokines, which promotes the initiation and maintenance of GVHD-associated Tcell activations. Even though it is well established that cytokines play an important role in the pathogenesis of GVHD, GVHD is a complex process that cannot be prevented with a single inflammatory cytokine inhibition as demonstrated previously (4). Thus, efficient methods to control the whole inflammatory milieu are needed.

Infectious diseases can theoretically contribute to an elevation of inflammatory cytokines after allogeneic HSCT (5-7). Possible interaction between viral infections and graft rejections of transplanted organ or GVHD are thought to be mediated by the alloreactivity of virus-specific T-cells (8,9). Bacterial infection can also induce GVHD rather non-specifically, considering the induction of systemic proinflammatory cytokines (10). The appropriate treatment or prophylaxis of bacterial infection during the early phase after allogeneic HSCT might be beneficial to reduce not only infection-related but also GVHD-related mortality. In terms of fungal infection, we could assume that the fungal infection is also implicated in the pathogenesis of acute GHVD, and recent reports suggested the implication of fungal infection in the pathogenesis of acute GVHD (11).

Here, we aim to review the literature addressing the interactions of bacterial infections and GVHD after allogeneic HSCT and discuss the potential benefits/disadvantages of published therapeutic options.

\section{INTERACTION BETWEEN BACTERIAL PRODUCTS AND GVHD IN MOUSE MODELS}

The fundamental work of van Bekkum and colleagues impressively demonstrated that activations of innate immunity by the gastrointestinal microflora are crucial and initiating steps in the induction of alloreactions. In animal models, mice grown under germ-free conditions and receiving bone marrow as a source of hematopoietic stem cells following total body irradiation did not develop acute GVHD (12). However, when a high number of T-cells were 
added, germ-free condition alone did not prevent but still delayed the onset of acute GVHD.

The role of bacterial products and the innate immune response in the pathophysiology of acute GVHD was nicely reviewed a

Table 1 | Combination of toll-like receptor and its ligand.

\begin{tabular}{|c|c|c|}
\hline TLR & Ligands & Recognized pathogens \\
\hline TLR1 & Triacyl lipopeptides & Bacteria \\
\hline TLR2 & $\begin{array}{l}\text { Lipoproteins, peptideglycan, } \\
\text { LTA, } \beta \text {-d-glucan, and mannan }\end{array}$ & Bacteria and fungus \\
\hline TLR3 & dsRNA & Virus \\
\hline TLR4 & $\begin{array}{l}\text { LPS, RSV fusion protein, } \\
\text { and mannans }\end{array}$ & GNR and virus \\
\hline TLR5 & Flagellin & Bacteria \\
\hline TLR6 & $\begin{array}{l}\text { Diacyl lipopeptides, LTA, } \\
\text { and } \beta \text {-d-glucan }\end{array}$ & Bacteria and fungus \\
\hline TLR7 & ssRNA & Virus, fungus, and bacteria \\
\hline TLR8 & ssRNA & Virus \\
\hline TLR9 & DNA and hemozoin & $\begin{array}{l}\text { Bacteria, fungus, virus, } \\
\text { and protozoan parasites }\end{array}$ \\
\hline TLR10 & Bacterial lipopeptide? & Bacteria? Virus? \\
\hline
\end{tabular}

LTA, lipoteichoic acid; LPS, lipopolysaccharide; RSV, respiratory syncytial virus; GNR, Gram-negative rod. decade ago (13). After tissue damage induced by the conditioning regimen, bacterial products contribute to an activation and expansion of donor-derived T-cells via antigen-presenting cells (APCs) (14). Such bacterial products are called as pathogen-associated molecular patterns (PAMPs) including lipopolysaccharide (LPS). In the activation of immune cells through a complex signaling cascade, toll-like receptors (TLRs) play an important role in recognizing PAMPs including LPS (15). The combination of TLR and their ligand is summarized in Table $\mathbf{1}$. In addition to TLRs, various nucleotide-binding and oligomerization domain (NOD)-like receptors (NLRs) play a vital role in innate immunity (16). Severe injury to tissues results in increased release of endotoxin and exacerbation of the inflammation. Bacterial infection itself is expected to stimulate the innate immunity similar to the tissue damage by the conditioning regimen (Figure 1). The stimulated APCs including dendritic cells and monocytes provoke an enhanced adaptive immunity by stimulating T-cells via antigen-specific signaling ( 7 , 15). Cooke and colleagues (17) reported that the sensitivity to LPS affected the severity of GVHD and idiopathic pneumonia syndrome in mice. They used two mouse strains which differ in their sensitivity to LPS and found that LPS-resistant recipients which had a genetic mutation in the TLR4 gene had significantly less lung injury and GVHD. These effects were associated with the reduction of TNF- $\alpha$ secretion $(17,18)$. They chose a direct approach to inhibit acute GVHD by using a direct competitive antagonist of endotoxin and by attenuation of the inflammatory response following transplantation, which improved GVHD score and survival (19). Mice were treated in the first 6 days after HSCT, when the donor T-cells are considered to be maximally stimulated by the host injury, and observed a concomitant reduction in inflammatory cytokine levels. This treatment was not

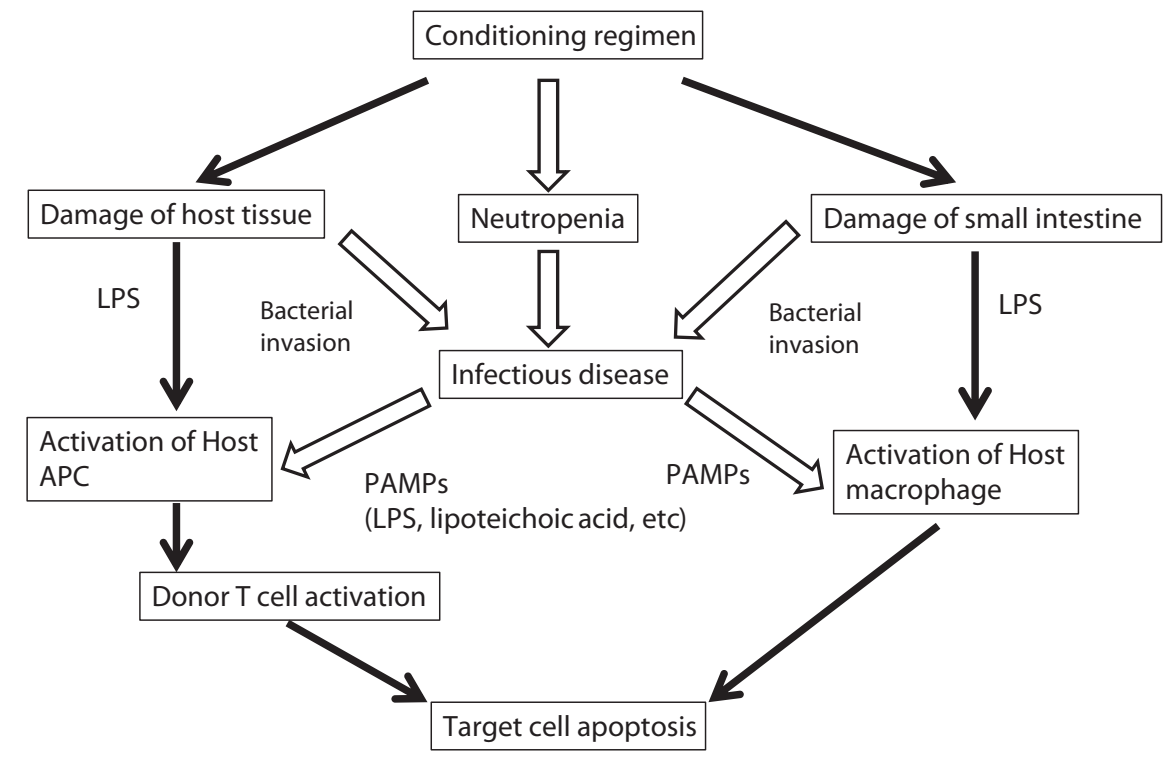

FIGURE 1 | Possible implication of bacterial infection in the pathogenesis of GVHD. Progression of acute GVHD can be summarized in three steps following the damage of host tissue by conditioning regimen: (1) activation of APCs; (2) donor T-cell activation, proliferation, differentiation, and migration; and (3) target tissue destruction. Injury to the gastrointestinal tract from conditioning causes systemic translocation of additional inflammatory stimuli, such as microbial products including LPS or other PAMPs, which further enhance activation of host APCs. In addition, conditioning regimen causes severe neutropenia that increased the risk of infectious disease. Infectious diseases increase the secretion of PAMPs, which activate host APCs. LPS, lipopolysaccharide; APC, antigen-presenting cell; PAMP, pathogen-associated molecular patterns. 
associated with a parallel suppression of the beneficial GVL effects, unlike non-specific immune suppression in this model. These experimental studies demonstrated the implication of LPS/TLR4 signaling in alloreaction.

As another signaling pathway, several studies using a mouse model demonstrated the importance of $\mathrm{CpG}$-containing DNA/TLR9 signaling. Calcaterra et al. (20) reported that survival and clinical score of acute GVHD in TLR9 knockout recipient mice were improved as compared with the wild-type recipient mice. Taylor et al. (21) also reported that the administration of CpGoligodeoxynucleotide, which mimic viral and bacterial DNA and are recognized by TLR9 markedly aggravated GVHD. In summary, these mouse models demonstrated the importance of bacterial products in the pathogenesis of acute GVHD.

\section{GUT BACTERIA AND GVHD}

It was reported that low bacterial environments strikingly limit the risk of GVHD in patients undergoing allogeneic HSCT (22). Beelen et al. assessed the influence of intestinal bacterial decontamination on the occurrence of grades II-IV acute GVHD retrospectively in 194 patients following HLA identical sibling marrow transplantation under conditions of strict protective isolation and intestinal antimicrobial decontamination (23). Using the duration of anaerobic growth suppression as a time-dependent explanatory variable, anaerobic decontamination was a significant independent predictor for grade IIIV acute GVHD (HR 1.7, 95\%CI 1.2-2.5, $P<0.05$ ). Following the promising finding, which suggested a beneficial effect of gut decontamination, a single-center open-label prospective study was conducted. A total of 134 marrow transplant recipients with hematologic malignancies were randomly assigned to a bacterial decontamination using metronidazole and ciprofloxacin $(n=68)$ or ciprofloxacin alone $(n=66)(24)$. Treatment was initiated on day 14 and was maintained until day 35 posttransplant. According to an intention-to-treat principle, 17 patients (25\%) randomized to the combined decontamination medication and 33 patients $(50 \%)$ randomized to ciprofloxacin alone developed grades II-IV GVHD $(P<0.05)$. The higher frequency of grades II-IV acute GVHD in patients randomized to ciprofloxacin alone resulted from a more than twofold increased number of patients developing liver or intestinal involvement with acute GVHD compared with patients randomized to the combined decontamination medication $(P<0.05)$. Regarding the addition of metronidazole, it might reduce the risk of Clostridium difficile infection (CDI), which has been reported to be associated with subsequent GVHD onset $(25,26)$. Alonso and colleagues reported that patients who developed CDI were more likely to develop GI GVHD compared with those who never developed CDI $(P<0.001)$. In this study, the diagnosis of CDI preceded the diagnosis of GI GVHD in the majority of patients (12 of 14 patients, $85.7 \%$ ). Among the 12 patients who developed GI GVHD following CDI, GI GVHD diagnosis occurred at a median of 21.5 days after CDI. Thus, gut decontamination might reduce the risk of acute GVHD. However, due to concerns about resistance or disturbance of the microbiota by prophylactic antibiotics, the type of antibiotics and the duration of prophylaxis have to be carefully discussed (27).
Correlation between the intestinal microbiome and autoimmune diseases has been demonstrated recently $(28,29)$. Even though there is not much data about the correlation between the intestinal microbiome and GVHD, it has been established that the microbiome has an influence on the status of immune cells (30). A recent report showed that the abundance of bacteria belonging to the genus Blautia, a commensal commonly found in the intestinal tract of humans, predicted for protection from severe GVHD in recipients of allogeneic HSCT (31). Furthermore, in murine models, introducing a species of Blautia of murine origin reduced GVHD severity. Intriguingly, loss of Blautia correlates strongly with reductions in oral nutritional intake in both humans and mice. Another group reported that loss of bacterial diversity was associated with use of systemic antibiotics and it was pronounced in patients with gastrointestinal GVHD (32). In addition, Candida colonization might be also important in the pathogenesis of GVHD (11). As a possible intervention to reduce the risk of GVHD, gut flora manipulation and nutritional intervention strategies might be promising. Previous reports showed that gut flora manipulation by Lactobacillales may reduce intestinal inflammation and improve outcomes for allogeneic HSCT recipients in a murine model $(33,34)$. It is worthy to test whether the manipulation of intestinal microbiome is able to reduce the risk of acute GVHD. Considering the considerable difference of conditioning regimen or GVHD prophylaxis in the regimen-related toxicity of oral mucosa and gastrointestinal tract, importance of gut bacterial manipulation might be more important in patients with a myeloablative conditioning regimen than those with a reducedintensity conditioning regimen, or in patients with short-term methotrexate than those with mycophenolate mofetil (35-40).

\section{BACTERIAL INFECTION AND GVHD}

Intensive chemotherapy and irradiation result in damage to the gastrointestinal tract, allowing bacteria to enter the systemic circulation. This results in stimulation of the host immune response by the production of inflammatory cytokines. Blood stream infection (BSI) is expected to promote the inflammatory conditions, which leads to an aggravation of acute GVHD. Statistically, it is difficult to assess the association between BSI and acute GVHD because acute GVHD itself is a risk factor of subsequent BSI. Poutsiaka and colleagues (41) found that early BSI was associated with an increased risk of grade II-IV acute GVHD.

As a marker of infectious disease, C-reactive protein (CRP) is routinely used in Europe and Japan (42-44). CRP is an acute phase reactant that is elevated in patients with infectious disease along with IL-6, the main cytokine that induces CRP release $(45,46)$. Even though CRP has a limited value for the differential diagnosis of bacterial infections due to the non-specific elevation in patients with inflammation from other causes, profound elevation of CRP early after HSCT was in general caused by infectious diseases (47-52). Considering the role of inflammation in the pathogenesis of GVHD, it is intriguing whether systemic inflammation caused by infection also exaggerates acute GVHD. Several retrospective studies assessed the association between the elevation of CRP and transplant complications including acute GVHD (50, 53-57). Our group reported that a significant elevation of CRP during the neutropenic period was associated with a 
Table 2 | Bacteria commonly found on the surfaces of the human body (64).

\begin{tabular}{lll}
\hline Oral cavity & Gut & Skin \\
\hline Streptococcus & Bacteroides & Propionibacterineae \\
Veillonella & Lachnospiraceae & Staphylococcus \\
Prevotella & Prevotella & Corynebacterineae \\
Pasteurellaceae & Faecalibacterium & Streptophyta \\
Neisseria & Lachnospiraceae & Micrococcineae \\
Fusobacterium & Ruminococcaceae & Streptococcus \\
Micrococcineae & Clostridiales & Finegoldia \\
Pasteurellaceae & Parabacteroides & Lactobacillus \\
Actinomycineae & Alistipes & Anaerococcus \\
Porphyromonas & Proteobacteria & Enhydrobacter
\end{tabular}

subsequent incidence of acute GVHD (50). Min et al. also reported that patients with GVHD had a significantly higher CRP level early after allogeneic HSCT compared to those without GVHD (56). Furthermore, Michigan group assessed plenty of biomarkers to establish a biomarker panel for the prediction of acute GVHD (58). Eight proteins (IL-2R $\alpha$, CRP, IL-8, ICAM-1, TIMP-1, TNFR1, HGF, and CA19.9) resulted in highly significant results $(P$-value $<0.01$ for two-sample $t$ tests comparing patients with and without GVHD). Among these eight biomarkers, CRP had the highest fold difference $(\times 5.44)$ and the second lowest $P$-value $\left(5.9 \times 10^{-6}\right)$ comparing patients with acute GVHD to those without acute GVHD, even though they excluded CRP probably considering that CRP is elevated in patients with infectious diseases. However, these results also indicate that the elevation of CRP preceded the incidence of acute GVHD. Taking the results into account that elevated CRP caused by infectious diseases precedes the occurrence of acute GVHD, strategies to improve prevention of infectious diseases early after allogeneic HSCT should be explored to reduce the risk of subsequent acute GVHD and subsequently necessary immunosuppressive therapy. Studies examining an intensified prophylaxis for bacterial infection early after allogeneic HSCT using intravenous antibiotics such as tazobactam/piperacillin (59), meropenem (60), vancomycin $(61,62)$, or teicoplanin (63) unfortunately did not report the incidence of acute GVHD, which would be important to evaluate different antibacterial strategies and their impact in GVHD incidence and severity. Although the information of bacteria commonly found on the surfaces of the human body might help us to choose the antibiotics (64) (Table 2), we need more information about bacteria commonly found after allogeneic HSCT $(27,32)$. Another possible intervention could be intensive glucose control and glutamine, which were reported to ameliorate the elevation of CRP level (65-67).

\section{GENETIC POLYMORPHISM IN GENES RELATING TO HOST-MICROBE RECOGNITION AND GVHD}

Recent genome-wide association studies (GWAS) have identified a large number of major loci, which are associated with various autoimmune diseases including Crohn's disease (CD), systemic lupus erythematosis (SLE), and others $(16,68,69)$. In terms of $\mathrm{CD}$, polymorphisms in NOD2 were reported to be associated with an increased risk of CD (70-72). In terms of
SLE, Graham and colleagues (73) reported that interferon regulatory factor 5 (IRF5) has been associated with SLE. IRF5 is downstream of pattern-recognition receptor (PRR) signaling and induces numerous cytokines.

Similar to the findings in the field of autoimmunity, several polymorphisms in PRRs were associated with posttransplant complications in HSCT (74). The incidence of severe GVHD in pairs with either donor or recipient NOD2 mutations was significantly higher compared to that in donor/recipient pairs without any NOD2 variant $(75,76)$.

Hildebrandt and colleagues (77) reported the association between polymorphisms in NOD2 and the risk of bronchiolitis obliterans, a severe form of chronic GVHD.

In addition, several papers reported the association between the polymorphisms in PRRs and other infections such as fungal and viral infection (78). Polymorphism in dectin-1, a C-type lectin receptor recognizing the $\beta$-1,3-glucan motif of Candida was associated with increased Candida colonization of HSCT recipients, rendering them at high risk for candidemia $(11,79)$. Polymorphism in dectin-1 was also reported to be associated with an increased risk of Aspergillus infection (80). In addition, Candida colonization was reported to be associated with an increased incidence of acute GVHD (11). In terms of viral infection, the report is limited up to now, but Jaskula and colleagues (78) reported that polymorphism of NOD2 was associated with an increased risk of herpes virus reactivation. Considering the implication of PRRs in the interplay of host cells with invading viruses $(81,82)$, more studies which assess the association between polymorphisms of PRRs and the incidence of viral infection and subsequent GVHD are warranted.

\section{POTENTIAL INTERVENTION TO REDUCE THE RISK OF GVHD}

There are several possible interventions to reduce the risk of GVHD, focusing on the control of pathways activated by bacterial infections. Several strategies such as manipulation of gut bacteria and nutritional support have been already discussed above.

One strategy is to target the pathway of TLRs and other molecules in innate immunity. There are several drugs targeting TLRs under development, for example TLR4 antagonists (Eritoran-E5564, TAK-242) and TLR2 antagonistic antibody (83). Although studies conducted in patients with sepsis using TLR4 antagonists did not demonstrate the efficacy of these drugs, they might be useful in the amelioration of GVHD. Intervention to reduce the level of damage-associated molecular patterns (DAMPs), known as alarmins might be also effective considering the common downstream pathway between PAMPs and DAMPs. DAMPs are endogenous components commonly released by injured or stressed cells, such as nucleic acids, uric acid (UA), HMGB-1, heparan sulfate (HS), etc. (84-86). Regarding UA, one study showed that urate oxidase can be safely administered during myeloablative conditioning and may reduce the incidence of acute GVHD (87). Regarding HS, treatment with the serine protease inhibitor al-antitrypsin decreased serum levels of HS, leading to a reduction in GVHD severity in mice (88).

Another strategy might be preemptive therapy using ATG, intra-arterial corticosteroids, and others. ATG has been tested in 
a prospective randomized study of preemptive GVHD treatment with ATG in 170 patients at high risk of GVHD (89-91). This study showed that a preemptive ATG significantly reduced the incidence of GVHD after an alternative donor HSCT. In terms of intraarterial corticosteroids, small studies demonstrated the promising effectiveness in patients with severe gut GVHD $(92,93)$. Such preemptive strategy can be applied if we develop a scoring system incorporating the status of immunity activated by PAMPs.

\section{DISCUSSION}

As described above, various experimental and clinical data strongly suggest the implications of bacterial, fungal, and viral infection and acute GVHD. One possible intervention might be the manipulation of intestinal microbiota. Various strategies can be used for this purpose, such as intensification of gut bacterial decontamination or administration of Lactobacillales. Gut bacterial decontamination is practically simple but the duration of decontamination should be as short as possible, considering the risk of emergence of resistant bacteria and the cost factors. Administration of Lactobacillales has not yet been proved to be safe in immunocompromised recipients after allogeneic HSCT.

In conclusion, various evidences from experimental models and clinical studies suggest the implication of bacterial infection in the pathogenesis of acute GVHD. To ameliorate the inflammation caused by bacterial infection, specific antibacterial strategies, treatment targeting the pathway of innate immunity, or nutritional interventions might help to reduce the risk of acute GVHD, which should be prospectively assessed in clinical trials.

\section{ACKNOWLEDGMENTS}

We thank the medical, nursing, data-processing, laboratory, and the clinical staff for their important contributions to our studies and their dedicated care of the patients.

\section{REFERENCES}

1. Gratwohl A, Brand R, Frassoni F, Rocha V, Niederwieser D, Reusser P, et al. Cause of death after allogeneic haematopoietic stem cell transplantation (HSCT) in early leukaemias: an EBMT analysis of lethal infectious complications and changes over calendar time. Bone Marrow Transplant (2005) 36(9):757-69. doi:10.1038/sj.bmt.1705140

2. van den Brink MR, Porter DL, Giralt S, Lu SX, Jenq RR, Hanash A, et al. Relapse after allogeneic hematopoietic cell therapy. Biol Blood Marrow Transplant (2010) 16(1 Suppl):S138-45. doi:10.1016/j.bbmt.2009.10.023

3. Duran-Struuck R, Reddy P. Biological advances in acute graft-versus-host disease after allogeneic hematopoietic stem cell transplantation. Transplantation (2008) 85(3):303-8. doi:10.1097/TP.0b013e318162d357

4. Hamadani M, Hofmeister CC, Jansak B, Phillips G, Elder P, Blum W, et al. Addition of infliximab to standard acute graft-versus-host disease prophylaxis following allogeneic peripheral blood cell transplantation. Biol Blood Marrow Transplant (2008) 14(7):783-9. doi:10.1016/j.bbmt.2008.04.006

5. Chong DL, Sriskandan S. Pro-inflammatory mechanisms in sepsis. Contrib Microbiol (2011) 17:86-107. doi:10.1159/000324022

6. Delsesto D, Opal SM. Future perspectives on regulating pro-and antiinflammatory responses in sepsis. Contrib Microbiol (2011) 17:137-56. doi:10. $1159 / 000324030$

7. Salomao R, Brunialti MK, Rapozo MM, Baggio-Zappia GL, Galanos C, Freudenberg M. Bacterial sensing, cell signaling, and modulation of the immune response during sepsis. Shock (2012) 38(3):227-42. doi:10.1097/SHK. 0b013e318262c4b0

8. Cainelli F, Vento S. Infections and solid organ transplant rejection: a cause-andeffect relationship? Lancet Infect Dis (2002) 2(9):539-49. doi:10.1016/S14733099(02)00370-5
9. Fuji S, Kapp M, Einsele H. Alloreactivity of virus-specific T cells: possible implication of graft-versus-host disease and graft-versus-leukemia effects. Front Immunol (2013) 4:330. doi:10.3389/fimmu.2013.00330

10. Lichtenstern C, Brenner T, Bardenheuer HJ, Weigand MA. Predictors of survival in sepsis: what is the best inflammatory marker to measure? Curr Opin Infect Dis (2012) 25(3):328-36. doi:10.1097/QCO.0b013e3283522038

11. van der Velden WJ, Netea MG, de Haan AF, Huls GA, Donnelly JP, Blijlevens NM. Role of the mycobiome in human acute graft-versus-host disease. Biol Blood Marrow Transplant (2013) 19(2):329-32. doi:10.1016/j.bbmt. 2012.11.008

12. van Bekkum DW, Knaan S. Role of bacterial microflora in development of intestinal lesions from graft-versus-host reaction. J Natl Cancer Inst (1977) 58(3):787-90.

13. Cooke KR, Olkiewicz K, Erickson N, Ferrara JL. The role of endotoxin and the innate immune response in the pathophysiology of acute graft versus host disease. J Endotoxin Res (2002) 8(6):441-8. doi:10.1179/096805102125001046

14. Ferrara JL, Levine JE, Reddy P, Holler E. Graft-versus-host disease. Lancet (2009) 373(9674):1550-61. doi:10.1016/S0140-6736(09)60237-3

15. Giamarellos-Bourboulis EJ, Raftogiannis M. The immune response to severe bacterial infections: consequences for therapy. Expert Rev Anti Infect Ther (2012) 10(3):369-80. doi:10.1586/eri.12.2

16. Zhong Y, Kinio A, Saleh M. Functions of NOD-like receptors in human diseases. Front Immunol (2013) 4:333. doi:10.3389/fimmu.2013.00333

17. Cooke KR, Hill GR, Crawford JM, Bungard D, Brinson YS, Delmonte J Jr, et al. Tumor necrosis factor- alpha production to lipopolysaccharide stimulation by donor cells predicts the severity of experimental acute graft-versus-host disease. J Clin Invest (1998) 102(10):1882-91. doi:10.1172/JCI4285

18. Cooke KR, Hill GR, Gerbitz A, Kobzik L, Martin TR, Crawford JM, et al. Hyporesponsiveness of donor cells to lipopolysaccharide stimulation reduces the severity of experimental idiopathic pneumonia syndrome: potential role for a gutlung axis of inflammation. J Immunol (2000) 165(11):6612-9.

19. Cooke KR, Gerbitz A, Crawford JM, Teshima T, Hill GR, Tesolin A, et al. LPS antagonism reduces graft-versus-host disease and preserves graft-versusleukemia activity after experimental bone marrow transplantation. J Clin Invest (2001) 107(12):1581-9. doi:10.1172/JCI12156

20. Calcaterra C, Sfondrini L, Rossini A, Sommariva M, Rumio C, Menard S, et al. Critical role of TLR9 in acute graft-versus-host disease. J Immunol (2008) 181(9):6132-9.

21. Taylor PA, Ehrhardt MJ, Lees CJ, Panoskaltsis-Mortari A, Krieg AM, Sharpe $\mathrm{AH}$, et al. TLR agonists regulate alloresponses and uncover a critical role for donor APCs in allogeneic bone marrow rejection. Blood (2008) 112(8):3508-16. doi:10.1182/blood-2007-09-113670

22. Storb R, Prentice RL, Buckner CD, Clift RA, Appelbaum F, Deeg J, et al. Graft-versus-host disease and survival in patients with aplastic anemia treated by marrow grafts from HLA-identical siblings. Beneficial effect of a protective environment. $N$ Engl J Med (1983) 308(6):302-7. doi:10.1056/ NEJM198302103080602

23. Beelen DW, Haralambie E, Brandt H, Linzenmeier G, Muller KD, Quabeck K, et al. Evidence that sustained growth suppression of intestinal anaerobic bacteria reduces the risk of acute graft-versus-host disease after sibling marrow transplantation. Blood (1992) 80(10):2668-76.

24. Beelen DW, Elmaagacli A, Muller KD, Hirche H, Schaefer UW. Influence of intestinal bacterial decontamination using metronidazole and ciprofloxacin or ciprofloxacin alone on the development of acute graft-versus-host disease after marrow transplantation in patients with hematologic malignancies: final results and long-term follow-up of an open-label prospective randomized trial. Blood (1999) 93(10):3267-75.

25. Alonso CD, Treadway SB, Hanna DB, Huff CA, Neofytos D, Carroll KC, et al. Epidemiology and outcomes of Clostridium difficile infections in hematopoietic stem cell transplant recipients. Clin Infect Dis (2012) 54(8):1053-63. doi:10.1093/cid/cir1035

26. Chakrabarti S, Lees A, Jones SG, Milligan DW. Clostridium difficile infection in allogeneic stem cell transplant recipients is associated with severe graftversus-host disease and non-relapse mortality. Bone Marrow Transplant (2000) 26(8):871-6. doi:10.1038/sj.bmt.1702627

27. Taur Y, Xavier JB, Lipuma L, Ubeda C, Goldberg J, Gobourne A, et al. Intestinal domination and the risk of bacteremia in patients undergoing allogeneic hematopoietic stem cell transplantation. Clin Infect Dis (2012) 55(7):905-14. doi:10.1093/cid/cis580 
28. Round JL, Mazmanian SK. The gut microbiota shapes intestinal immune responses during health and disease. Nat Rev Immunol (2009) 9(5):313-23. doi:10.1038/nri2515

29. Kranich J, Maslowski KM, Mackay CR. Commensal flora and the regulation of inflammatory and autoimmune responses. Semin Immunol (2011) 23(2):139-45. doi:10.1016/j.smim.2011.01.011

30. Hooper LV, Littman DR, Macpherson AJ. Interactions between the microbiota and the immune system. Science (2012) 336(6086):1268-73. doi:10.1126/ science. 1223490

31. Jenq R, Marcel RM. Identification of intestinal commensal bacteria protective against GVHD in mice and humans. Biol Blood Marrow Transplant (2014) 20(2):S22-3. doi:10.1016/j.bbmt.2013.12.003

32. Holler E, Butzhammer P, Schmid K, Hundsrucker C, Koestler J, Peter K, et al Metagenomic analysis of the stool microbiome in patients receiving allogeneic stem cell transplantation: loss of diversity is associated with use of systemic antibiotics and more pronounced in gastrointestinal graft-versus-host disease. Biol Blood Marrow Transplant (2014) 20(5):640-45. doi:10.1016/j.bbmt.2014. 01.030

33. Jenq RR, Ubeda C, Taur Y, Menezes CC, Khanin R, Dudakov JA, et al. Regulation of intestinal inflammation by microbiota following allogeneic bone marrow transplantation. J Exp Med (2012) 209(5):903-11. doi:10.1084/jem. 20112408

34. Gerbitz A, Schultz M, Wilke A, Linde HJ, Scholmerich J, Andreesen R, et al. Probiotic effects on experimental graft-versus-host disease: let them eat yogurt. Blood (2004) 103(11):4365-7. doi:10.1182/blood-2003-11-3769

35. Ram R, Yeshurun M, Vidal L, Shpilberg O, Gafter-Gvili A. Mycophenolate mofetil vs. methotrexate for the prevention of graft-versus-host-disease - systematic review and meta-analysis. Leuk Res (2014) 38(3):352-60. doi:10.1016/j.leukres. 2013.12.012

36. Bolwell B, Sobecks R, Pohlman B, Andresen S, Rybicki L, Kuczkowski E, et al. A prospective randomized trial comparing cyclosporine and short course methotrexate with cyclosporine and mycophenolate mofetil for GVHD prophylaxis in myeloablative allogeneic bone marrow transplantation. Bone Marrow Transplant (2004) 34(7):621-5. doi:10.1038/sj.bmt.1704647

37. Pinana JL, Valcarcel D, Fernandez-Aviles F, Martino R, Rovira M, Barba P, et al. MTX or mycophenolate mofetil with CsA as GVHD prophylaxis after reducedintensity conditioning PBSCT from HLA-identical siblings. Bone Marrow Transplant (2010) 45(9):1449-56. doi:10.1038/bmt.2009.362

38. Neumann F, Graef T, Tapprich C, Vaupel M, Steidl U, Germing U, et al. Cyclosporine A and mycophenolate mofetil vs cyclosporine A and methotrexate for graft-versus-host disease prophylaxis after stem cell transplantation from HLA-identical siblings. Bone Marrow Transplant (2005) 35(11):1089-93. doi:10.1038/sj.bmt.1704956

39. Goldberg J, Jacobsohn DA, Zahurak ML, Vogelsang GB. Gastrointestinal toxicity from the preparative regimen is associated with an increased risk of graft-versus-host disease. Biol Blood Marrow Transplant (2005) 11(2):101-7. doi:10.1016/j.bbmt.2004.10.007

40. Liu D, Yan C, Xu L, Wang Y, Han W, Zhang X, et al. Diarrhea during the conditioning regimen is correlated with the occurrence of severe acute graft-versushost disease through systemic release of inflammatory cytokines. Biol Blood Marrow Transplant (2010) 16(11):1567-75. doi:10.1016/j.bbmt.2010.05.001

41. Poutsiaka DD, Munson D, Price LL, Chan GW, Snydman DR. Blood stream infection (BSI) and acute GVHD after hematopoietic SCT (HSCT) are associated. Bone Marrow Transplant (2011) 46(2):300-7. doi:10.1038/bmt.2010.112

42. Faix JD. Biomarkers of sepsis. Crit Rev Clin Lab Sci (2013) 50(1):23-36. doi: $10.3109 / 10408363.2013 .764490$

43. Sankar V, Webster NR. Clinical application of sepsis biomarkers. J Anesth (2013) 27(2):269-83. doi:10.1007/s00540-012-1502-7

44. Chan T, Gu F. Early diagnosis of sepsis using serum biomarkers. Expert Rev Mol Diagn (2011) 11(5):487-96. doi:10.1586/ERM.11.26

45. Gabay C, Kushner I. Acute-phase proteins and other systemic responses to inflammation. $N$ Engl J Med (1999) 340(6):448-54. doi:10.1056/ NEJM199902113400607

46. Bode JG, Albrecht U, Haussinger D, Heinrich PC, Schaper F. Hepatic acute phase proteins - regulation by IL-6- and IL-1-type cytokines involving STAT3 and its crosstalk with NF-kappaB-dependent signaling. Eur J Cell Biol (2012) 91(6-7):496-505. doi:10.1016/j.ejcb.2011.09.008

47. Ram R, Yeshurun M, Farbman L, Herscovici C, Shpilberg O, Paul M. Elevation of CRP precedes clinical suspicion of bloodstream infections in patients undergoing hematopoietic cell transplantation. J Infect (2013) 67(3):194-8. doi:10.1016/j.jinf.2013.05.005

48. Hong J, Moon SM, Ahn HK, Sym SJ, Park YS, Park J, et al. Comparison of characteristics of bacterial bloodstream infection between adult patients with allogeneic and autologous hematopoietic stem cell transplantation. Biol Blood Marrow Transplant (2013) 19(6):994-9. doi:10.1016/j.bbmt.2013.03.019

49. Mori Y, Miyawaki K, Kato K, Takenaka K, Iwasaki H, Harada N, et al. Diagnostic value of serum procalcitonin and C-reactive protein for infections after allogeneic hematopoietic stem cell transplantation versus nontransplant setting. Intern Med (2011) 50(19):2149-55. doi:10.2169/internalmedicine.50. 5798

50. Fuji S, Kim SW, Fukuda T, Mori S, Yamasaki S, Morita-Hoshi Y, et al. Preengraftment serum $\mathrm{C}$-reactive protein (CRP) value may predict acute graftversus-host disease and nonrelapse mortality after allogeneic hematopoietic stem cell transplantation. Biol Blood Marrow Transplant (2008) 14(5):510-7. doi:10.1016/j.bbmt.2008.02.008

51. Hambach L, Eder M, Dammann E, Schrauder A, Sykora KW, Dieterich C, et al. Diagnostic value of procalcitonin serum levels in comparison with Creactive protein in allogeneic stem cell transplantation. Haematologica (2002) 87(6):643-51.

52. McNeer JL, Kletzel M, Rademaker A, Alford K, O’Day K, Schaefer C, et al. Early elevation of $\mathrm{C}$-reactive protein correlates with severe infection and nonrelapse mortality in children undergoing allogeneic stem cell transplantation. Biol Blood Marrow Transplant (2010) 16(3):350-7. doi:10.1016/j.bbmt.2009.10.036

53. Schots R, Kaufman L, Van Riet I, Ben Othman T, De Waele M, Van Camp B, et al. Proinflammatory cytokines and their role in the development of major transplant-related complications in the early phase after allogeneic bone marrow transplantation. Leukemia (2003) 17(6):1150-6. doi:10.1038/sj.leu.2402946

54. Schots R, Van Riet I, Othman TB, Trullemans F, De Waele M, Van Camp B, et al. An early increase in serum levels of C-reactive protein is an independent risk factor for the occurrence of major complications and 100-day transplantrelated mortality after allogeneic bone marrow transplantation. Bone Marrow Transplant (2002) 30(7):441-6. doi:10.1038/sj.bmt.1703672

55. Pihusch M, Pihusch R, Fraunberger P, Pihusch V, Andreesen R, Kolb HJ, et al. Evaluation of C-reactive protein, interleukin-6, and procalcitonin levels in allogeneic hematopoietic stem cell recipients. Eur J Haematol (2006) 76(2):93-101. doi:10.1111/j.0902-4441.2005.00568.x

56. Min CK, Kim SY, Eom KS, Kim YJ, Kim HJ, Lee S, et al. Patterns of Creactive protein release following allogeneic stem cell transplantation are correlated with leukemic relapse. Bone Marrow Transplant (2006) 37(5):493-8. doi:10.1038/sj.bmt.1705276

57. Ryu J, Lee SR, Park SG, Kang S, Kim HJ, Park BC. Change in serum proteome during allogeneic hematopoietic stem cell transplantation and clinical significance of serum C-reactive protein and haptoglobin. Exp Mol Med (2010) 42(9):651-61. doi:10.3858/emm.2010.42.9.065

58. Paczesny S, Krijanovski OI, Braun TM, Choi SW, Clouthier SG, Kuick R, et al. A biomarker panel for acute graft-versus-host disease. Blood (2009) 113(2):273-8. doi:10.1182/blood-2008-07-167098

59. Kroschinsky F, Wichmann G, Bornhauser M, Ordemann R, Schuler U, Ehninger $\mathrm{G}$, et al. Efficacy and tolerability of prophylactic treatment with intravenous piperacillin/tazobactam in patients undergoing hematopoietic stem cell transplantation. Transpl Infect Dis (2002) 4(3):132-6. doi:10.1034/j.1399-3062.2002. t01-1-01014.x

60. Perez-Simon JA, Garcia-Escobar I, Martinez J, Vazquez L, Caballero D, Canizo $\mathrm{C}$, et al. Antibiotic prophylaxis with meropenem after allogeneic stem cell transplantation. Bone Marrow Transplant (2004) 33(2):183-7. doi:10.1038/sj.bmt. 1704335

61. Jaffe D, Jakubowski A, Sepkowitz K, Sebti R, Kiehn TE, Pamer E, et al. Prevention of peritransplantation viridans streptococcal bacteremia with early vancomycin administration: a single-center observational cohort study. Clin Infect Dis (2004) 39(11):1625-32. doi:10.1086/425612

62. Arns da Cunha C, Weisdorf D, Shu XO, DeFor T, Pastor JD III, Johnson JR. Early Gram-positive bacteremia in BMT recipients: impact of three different approaches to antimicrobial prophylaxis. Bone Marrow Transplant (1998) 21(2):173-80. doi:10.1038/sj.bmt.1701057

63. Mori T, Shimizu T, Kato J, Kikuchi T, Kohashi S, Koda Y, et al. Nephrotoxicity of concomitant use of tacrolimus and teicoplanin in allogeneic hematopoietic stem cell transplant recipients. Transpl Infect Dis (2014) 16(2):329-32. doi:10.1111/tid.12185 
64. Costello EK, Lauber CL, Hamady M, Fierer N, Gordon JI, Knight R. Bacterial community variation in human body habitats across space and time. Science (2009) 326(5960):1694-7. doi:10.1126/science.1177486

65. Fuji S, Kim SW, Mori S, Kamiya S, Yoshimura K, Yokoyama H, et al. Intensive glucose control after allogeneic hematopoietic stem cell transplantation: a retrospective matched-cohort study. Bone Marrow Transplant (2009) 44(2):105-11. doi:10.1038/bmt.2008.431

66. Blijlevens NM, Donnelly JP, Naber AH, Schattenberg AV, DePauw BE. A randomised, double-blinded, placebo-controlled, pilot study of parenteral glutamine for allogeneic stem cell transplant patients. Support Care Cancer (2005) 13(10):790-6. doi:10.1007/s00520-005-0790-y

67. Hansen TK, Thiel S, Wouters PJ, Christiansen JS, Van den Berghe G. Intensive insulin therapy exerts antiinflammatory effects in critically ill patients and counteracts the adverse effect of low mannose-binding lectin levels. J Clin Endocrinol Metab (2003) 88(3):1082-8. doi:10.1210/jc.2002-021478

68. Zenewicz LA, Abraham C, Flavell RA, Cho JH. Unraveling the genetics of autoimmunity. Cell (2010) 140(6):791-7. doi:10.1016/j.cell.2010.03.003

69. Deng Y, Tsao BP. Genetic susceptibility to systemic lupus erythematosus in the genomic era. Nat Rev Rheumatol (2010) 6(12):683-92. doi:10.1038/nrrheum. 2010.176

70. Hugot JP, Chamaillard M, Zouali H, Lesage S, Cezard JP, Belaiche J, et al. Association of NOD2 leucine-rich repeat variants with susceptibility to Crohn's disease. Nature (2001) 411(6837):599-603. doi:10.1038/35079107

71. Ogura Y, Bonen DK, Inohara N, Nicolae DL, Chen FF, Ramos R, et al. A frameshift mutation in NOD2 associated with susceptibility to Crohn's disease. Nature (2001) 411(6837):603-6. doi:10.1038/35079114

72. Hampe J, Cuthbert A, Croucher PJ, Mirza MM, Mascheretti S, Fisher S, et al. Association between insertion mutation in NOD2 gene and Crohn's disease in German and British populations. Lancet (2001) 357(9272):1925-8. doi:10.1016/s0140-6736(00)05063-7

73. Graham RR, Kozyrev SV, Baechler EC, Reddy MV, Plenge RM, Bauer JW, et al. A common haplotype of interferon regulatory factor 5 (IRF5) regulates splicing and expression and is associated with increased risk of systemic lupus erythematosus. Nat Genet (2006) 38(5):550-5. doi:10.1038/ng1782

74. Henckaerts L, Vermeire S. NOD2/CARD15 disease associations other than Crohn's disease. Inflamm Bowel Dis (2007) 13(2):235-41. doi:10.1002/ibd.20066

75. Holler E, Rogler G, Herfarth H, Brenmoehl J, Wild PJ, Hahn J, et al. Both donor and recipient NOD2/CARD15 mutations associate with transplant-related mortality and GVHD following allogeneic stem cell transplantation. Blood (2004) 104(3):889-94. doi:10.1182/blood-2003-10-3543

76. Holler E, Rogler G, Brenmoehl J, Hahn J, Herfarth H, Greinix H, et al. Prognostic significance of NOD2/CARD15 variants in HLA-identical sibling hematopoietic stem cell transplantation: effect on long-term outcome is confirmed in 2 independent cohorts and may be modulated by the type of gastrointestinal decontamination. Blood (2006) 107(10):4189-93. doi:10.1182/blood2005-09-3741

77. Hildebrandt GC, Granell M, Urbano-Ispizua A, Wolff D, Hertenstein B, Greinix HT, et al. Recipient NOD2/CARD15 variants: a novel independent risk factor for the development of bronchiolitis obliterans after allogeneic stem cell transplantation. Biol Blood Marrow Transplant (2008) 14(1):67-74. doi:10.1016/j.bbmt. 2007.09.009

78. Jaskula E, Lange A, Kyrcz-Krzemien S, Markiewicz M, Dzierzak-Mietla M, Jedrzejczak WW, et al. NOD2/CARD15 single nucleotide polymorphism 13 (3020insC) is associated with risk of sepsis and single nucleotide polymorphism $8(2104 \mathrm{C}>\mathrm{T})$ with herpes viruses reactivation in patients after allogeneic hematopoietic stem cell transplantation. Biol Blood Marrow Transplant (2014) 20(3):409-14. doi:10.1016/j.bbmt.2013.12.558

79. Plantinga TS, van der Velden WJ, Ferwerda B, van Spriel AB, Adema G, Feuth T, et al. Early stop polymorphism in human DECTIN-1 is associated with increased Candida colonization in hematopoietic stem cell transplant recipients. Clin Infect Dis (2009) 49(5):724-32. doi:10.1086/604714

80. Cunha C, Di Ianni M, Bozza S, Giovannini G, Zagarella S, Zelante T, et al. Dectin-1 Y238X polymorphism associates with susceptibility to invasive aspergillosis in hematopoietic transplantation through impairment of both recipient- and donor-dependent mechanisms of antifungal immunity. Blood (2010) 116(24):5394-402. doi:10.1182/blood-2010-04-279307

81. Lester SN, Li K. Toll-like receptors in antiviral innate immunity. J Mol Biol (2014) 426(6):1246-64. doi:10.1016/j.jmb.2013.11.024

82. Lupfer C, Kanneganti TD. The expanding role of NLRs in antiviral immunity. Immunol Rev (2013) 255(1):13-24. doi:10.1111/imr.12089

83. Savva A, Roger T. Targeting toll-like receptors: promising therapeutic strategies for the management of sepsis-associated pathology and infectious diseases. Front Immunol (2013) 4:387. doi:10.3389/fimmu.2013.00387

84. Geddes K, Magalhaes JG, Girardin SE. Unleashing the therapeutic potential of NOD-like receptors. Nat Rev Drug Discov (2009) 8(6):465-79. doi:10.1038/ $\operatorname{nrd} 2783$

85. Rock KL, Kataoka H, Lai JJ. Uric acid as a danger signal in gout and its comorbidities. Nat Rev Rheumatol (2013) 9(1):13-23. doi:10.1038/nrrheum.2012.143

86. Ghaemi-Oskouie F, Shi Y. The role of uric acid as an endogenous danger signal in immunity and inflammation. Curr Rheumatol Rep (2011) 13(2):160-6. doi:10.1007/s11926-011-0162-1

87. Yeh AC, Brunner AM, Spitzer TR, Chen YB, Coughlin E, McAfee S, et al. Phase I study of urate oxidase in the reduction of acute graft-vs-host disease following myeloablative allogeneic stem cell transplantation. Biol Blood Marrow Transplant (2014) 20(5):730-4. doi:10.1016/j.bbmt.2014.02.003

88. Brennan TV, Lin L, Huang X, Cardona DM, Li Z, Dredge K, et al. Heparan sulfate, an endogenous TLR4 agonist, promotes acute GVHD after allogeneic stem cell transplantation. Blood (2012) 120(14):2899-908. doi:10.1182/blood-201107-368720

89. Sormani MP, Oneto R, Bruno B, Fiorone M, Lamparelli T, Gualandi F, et al. A revised day +7 predictive score for transplant-related mortality: serum cholinesterase, total protein, blood urea nitrogen, gamma glutamyl transferase, donor type and cell dose. Bone Marrow Transplant (2003) 32(2):205-11. doi:10.1038/sj.bmt.1704085

90. Bacigalupo A, Lamparelli T, Milone G, Sormani MP, Ciceri F, Peccatori J, et al. Pre-emptive treatment of acute GVHD: a randomized multicenter trial of rabbit anti-thymocyte globulin, given on day +7 after alternative donor transplants. Bone Marrow Transplant (2010) 45(2):385-91. doi:10.1038/bmt.2009.151

91. Bacigalupo A, Oneto R, Lamparelli T, Gualandi F, Bregante S, Raiola AM, et al. Pre-emptive therapy of acute graft-versus-host disease: a pilot study with antithymocyte globulin (ATG). Bone Marrow Transplant (2001) 28(12):1093-6. doi:10.1038/sj.bmt.1703306

92. Shapira MY, Bloom AI, Or R, Sasson T, Nagler A, Resnick IB, et al. Intra-arterial catheter directed therapy for severe graft-versus-host disease. $\mathrm{Br} J$ Haematol (2002) 119(3):760-4. doi:10.1046/j.1365-2141.2002.03923.x

93. Burgler D, Medinger M, Passweg J, Fischmann A, Bucher C. Intraarterial catheter guided steroid administration for the treatment of steroidrefractory intestinal GVHD. Leuk Res (2014) 38(2):184-7. doi:10.1016/j.leukres. 2013.10.024

Conflict of Interest Statement: The authors declare that the research was conducted in the absence of any commercial or financial relationships that could be construed as a potential conflict of interest.

Received: 01 February 2014; accepted: 10 April 2014; published online: 24 April 2014. Citation: Fuji S, Kapp $M$ and Einsele $H$ (2014) Possible implication of bacterial infection in acute graft-versus-host disease after allogeneic hematopoietic stem cell transplantation. Front. Oncol. 4:89. doi: 10.3389/fonc.2014.00089

This article was submitted to Hematology Oncology, a section of the journal Frontiers in Oncology.

Copyright (C) 2014 Fuji, Kapp and Einsele. This is an open-access article distributed under the terms of the Creative Commons Attribution License (CC BY). The use, distribution or reproduction in other forums is permitted, provided the original author(s) or licensor are credited and that the original publication in this journal is cited, in accordance with accepted academic practice. No use, distribution or reproduction is permitted which does not comply with these terms. 